\title{
Asynchronous Telepsychiatry: A Component of Stepped Integrated Care
}

Peter Yellowlees, MBBS, MD, ${ }^{1}$ Michelle Burke Parish, MA, $\operatorname{PhD}(\mathrm{c}){ }_{1}{ }^{1,2}$ Álvaro González, MA, ${ }^{1}$ Steven Chan, MD, MBA, ${ }^{1}$ Don Hilty, $M D_{1}{ }^{3}$ Ana-Maria losif, PhD, ${ }^{1}$ Robert McCarron, DO, ${ }^{1}$ Alberto Odor, MD, Lorin Scher, MD, ${ }^{1}$ Andrés Sciolla, MD, Jay Shore, $M D_{1}{ }^{4}$ and Glen Xiong $M D^{1}$

${ }^{1}$ Department of Psychiatry, University of California, Davis, Sacramento, California.

${ }^{2}$ The Betty Irene Moore School of Nursing, University of California, Davis, Sacramento, California.

${ }^{3}$ Department of Psychiatry, Keck School of Medicine, University of Southern California, Visalia, California.

${ }^{4}$ Department of Psychiatry, University of Colorado Denver, Aurora, Colorado.

\section{Abstract}

Objective: Integrated behavioral healthcare models typically involve a range of consultation options for mental healthcare. Asynchronous telepsychiatry (ATP) consults may be an additional potential choice, so we are conducting a 5-year clinical trial comparing ATP with synchronous telepsychiatry (STP) consultations.

Methods: Patients referred by primary care providers are randomly assigned to one of the two treatment groups, ATP or STP. Clinical outcome, satisfaction, and economic data are being collected from patients for 2 years at 6-month intervals. Results: Baseline characteristics for the first 158 patients and case examples of ATP are presented.

Conclusion: Implementing ATP in existing integrated behavioral healthcare models could make mental healthcare more efficient.

Keywords: telepsychiatry, telehealth, behavioral health, telemedicine

\section{Introduction}

I ntegrated behavioral healthcare is a comprehensive approach to care that comprises a team of primary care providers (PCPs) and behavioral health providers, working together in the primary care setting with patients and families, and using a systematic and cost-effective approach to provide patient-centered care for a defined population. ${ }^{1}$ Stepped care allows for the adoption of the most appropriate intervention for the type and severity of illness to increase the efficiency of care provision. ${ }^{2,3}$ Improving clinical workflows across primary and specialty care using stepped choices of electronic solutions can make mental healthcare more efficient. ${ }^{4}$

Integrated care models involve the development of patient registries: team-based clinical reviews of panels of patients and online provider-to-provider e-consultations and electronic versions of the traditional curbside consultation. Technologies such as electronic medical records (EMRs), e-mail, telephone, and secure electronic messaging through patient portals have created a series of electronically supported consultation choices for patients ${ }^{4}$ and providers. ${ }^{5}$ When PCPs are able to combine direct care with synchronous and asynchronous consultation options, a multitude of care possibilities become available, enabling a more flexible and stepped care structure in the integrated patient-centered medical home (IPCMH). ${ }^{6}$ Stepped models of care ideally use less intensive/expensive interventions at the outset, and then graduate to more intensive services if patients fail to improve. ${ }^{7,8}$ Synchronous telepsychiatry (STP) is an alternative to a traditional in-person consultation and has been shown to be as effective as in-person consultations for individuals suffering from mental illness. ${ }^{9-12}$

In recent years, we have tested asynchronous telepsychiatry (ATP) consultations as an additional potential choice and step in the referral options available for PCPs. ATP consultations comprise a video recording of a semistructured psychiatric patient interview conducted by a trained clinician in a primary care clinic, which is securely sent to a psychiatrist for a consultation opinion that then enables the patient's PCP to carry out treatment recommendations. ${ }^{13}$ ATP avoids the administrative barriers of STP ${ }^{13,14}$ and in-person care ${ }^{13,15,16}$ because it is simpler and much faster than arranging either of these types of consultations. An added advantage of the ATP approach is that it is more data rich than any other type of consultation. ATP involves a video recording of the patient and a stored objective recording of a patient's mental status examination.

A 5-year study, currently underway at the University of California (UC) Davis Medical Center and funded by the Agency for Healthcare Research and Quality, is the first clinical outcomes-based study of ATP and aims to investigate the clinical validity of the ATP model integrated into primary care. This article presents characteristics at baseline of the first 158 patients in this novel clinical trial of ATP compared with STP consultations. We are hoping to reach a target enrollment 


\section{YELLOWLEES ET AL.}

Table 1. Baseline Demographic and Clinical Characteristics of the First 158 Enrolled Participants

\begin{tabular}{|c|c|c|c|}
\hline & $\begin{array}{c}\text { ATP } \\
(N=77)\end{array}$ & $\begin{array}{c}\text { STP } \\
(N=81)\end{array}$ & $P^{\mathrm{a}}$ \\
\hline Age & $52.9 \pm 14.8$ & $51.8 \pm 15.1$ & 0.65 \\
\hline Diagnosis, $n(\%)$ & & & 0.99 \\
\hline Mood disorder & $53(69)$ & $53(65)$ & \\
\hline Anxiety disorder & 14 (18) & $16(20)$ & \\
\hline Substance abuse & $1(1)$ & $2(2)$ & \\
\hline Other & $9(12)$ & $10(12)$ & \\
\hline Gender, $n(\%)$ & & & 0.49 \\
\hline Female & $55(71)$ & $53(65)$ & \\
\hline Male & $22(29)$ & $28(36)$ & \\
\hline Ethnicity, $n(\%)^{1}$ & & & 0.51 \\
\hline African American, non-Hispanic & $0(0)$ & $2(3)$ & \\
\hline African American, Hispanic & $1(1)$ & $0(0)$ & \\
\hline Asian, non-Hispanic & $0(0)$ & $1(1)$ & \\
\hline Caucasian, Hispanic & 6 (8) & 7 (9) & \\
\hline Caucasian, non-Hispanic & $66(86)$ & $63(79)$ & \\
\hline Other, non-Hispanic & $0(0)$ & $2(3)$ & \\
\hline Other, Hispanic & $4(5)$ & $5(6)$ & \\
\hline Clinic site, $n(\%)$ & & & 0.97 \\
\hline Auburn & $44(57)$ & $48(59)$ & \\
\hline J Street (Sacramento) & $20(26)$ & $19(23)$ & \\
\hline Communicare & $13(17)$ & $14(17)$ & \\
\hline Current $\mathrm{MH}$ treatment, $n(\%)^{2}$ & & & 0.87 \\
\hline Yes & $26(35)$ & $30(37)$ & \\
\hline No & $49(65)$ & $51(63)$ & \\
\hline Current medication, $n(\%)^{3}$ & & & 0.84 \\
\hline Yes & $60(81)$ & $67(83)$ & \\
\hline No & $14(19)$ & $14(17)$ & \\
\hline Education, $n(\%)^{4}$ & & & 0.04 \\
\hline Graduate high school or less & $19(30)$ & $10(15)$ & \\
\hline Some college/2-year college & $23(36)$ & $37(56)$ & \\
\hline College/graduate school & $22(34)$ & $19(29)$ & \\
\hline Marital status, $n(\%)^{5}$ & & & 1.00 \\
\hline Married/relationship & $37(56)$ & $36(56)$ & \\
\hline Not in a relationship & $29(44)$ & $22(54)$ & \\
\hline
\end{tabular}

${ }^{a}$ Group characteristics were tested using two-sample $t$-test for age and Fisher's exact tests for association for categorical variables. Owing to rounding, percentages might not sum to 100 .

${ }^{1}$ Frequency missing $=1$ in STP group

${ }^{2}$ Frequency missing $=2$ in ATP group

Frequency missing $=3$ in ATP group

${ }^{4}$ Frequency missing $=13$ in ATP and 15 in STP group.

${ }^{5}$ Frequency missing $=11$ in ATP and 17 in STP group.

ATP, asynchronous telepsychiatry; STP, synchronous telepsychiatry. of 200 patients. We also present three case study examples that demonstrate how the ATP process is an efficient and effective choice within the model of integrated stepped care.

\section{Methods}

The clinical trial protocol was approved by the UC Davis Institutional Review Board (Clinical Trials registration NCT02084979). PCPs were informed of the study through project presentations at their clinics and through direct mail/e-mail or phone invitation. The participating providers were asked to refer primary care patients with any psychiatric disorder (typically depression, anxiety, or substance use that they believed would benefit from an assessment and monitoring psychiatric consultation every 6 months for 2 years. Participating providers were asked not to refer patients who were acutely dangerous to themselves or others or who had significant cognitive impairment. After consent, patients were randomized to one of two treatment groups (ATP or STP) stratified by primary presenting diagnosis on the Structured Clinical Interview for DSM-IV. ${ }^{17}$

The ATP arm (treatment condition) interviews were conducted by an ATP-trained clinician at the patient's PCP clinic utilizing basic components and key concepts of the psychiatric interview by Scher et al.'s ${ }^{18}$ motivational interviewing techniques, and supportive therapy when warranted. This interview was video recorded. In addition to providing the entire interview video, the interviewers noted the video segments they deemed clinically relevant or where important material was being discussed. After reviewing the patient video (typically about 3045 min long), all written data provided by the ATP interviewer, and the patient's EMR, a research psychiatrist provided a written assessment and psychiatric treatment plan in the EMR, which the PCPs then discussed with their patient before making decisions on the treatment recommendations. The PCPs had continuing access to the psychiatrist by EMR messaging, phone, or e-mail between all consultations. Comparatively, in the STP Arm (control condition), the consultation and communication process with the PCP was the same as for the ATP consultations, except that subjects were directly assessed by a psychiatrist using STP instead of ATP. In both arms, patients are being followed up for up to 2 years, each receiving five ATP or five STP consultations at 6 monthly intervals with clinical outcome, satisfaction, and economic data being collected continuously.

\section{Results}

The demographic characteristics for the first 158 participants enrolled in the study in both groups are presented in Table 1. The groups are balanced on most characteristics, with the only exception being that the ATP patients are somewhat 
Table 2. Case Studies of Asynchronous Telepsychiatry

A 54-year-old man, Brian, was referred for alcohol abuse and depression. In the interview, Brian stated that he had a long history of alcohol use and that since he stopped drinking 2 months previously, despite regular attendance at Alcoholics Anonymous, his depression had increased. Brian's ATP consultation occurred within a few days of referral, and the psychiatrist was able to send his recommendations of sertraline for depression and naltrexone for alcohol use disorder to the primary care physician within 3 days. The PCP agreed with the recommendations and was able follow-up with Brian a few days later to implement them.

This case demonstrates that ATP consultations can be completed in a fraction of the time that a patient would typically wait to see a psychiatrist where average wait times for a first time psychiatry visit were reported to be 25 days in $2014 .{ }^{19}$

\begin{tabular}{l}
\hline $\begin{array}{l}\text { Angela, a 67-year-old woman had a history of depression that had increased in the past } 2 \text { years due to her overwhelming medical problems and dissatisfaction with } \\
\text { her marriage. Throughout the long interview, her thought process was tangential and circumstantial often going off topic for lengthy amounts of time. After the } \\
\text { interview, the clinician noted down times Angela spoke about relevant information pertaining to antidepressant medications, her changes in affect, and her specific } \\
\text { psychiatric and medical symptoms. This allowed the psychiatrist as he reviewed the video, to jump to the specific times noted by the interviewer making his review } \\
\text { more efficient, and enabling him to more rapidly assess this highly circumstantial individual, provide a diagnosis of bipolar disorder, and develop a treatment plan } \\
\text { for her PCP. }\end{array}$ \\
This case demonstrates one way that ATP consults can lead to more efficient use of the time of psychiatrists who are the most expensive mental health providers. \\
\hline $\begin{array}{l}\text { Janet, was a 50-year-old female with multiple sclerosis, depression, and chronic pain. She was referred to the study for assessment of her cognition and memory } \\
\text { difficulties, which she thought were "possible ADHD." During her first ATP consult, she reported slowly worsening cognitive symptoms and minimal depressive } \\
\text { symptoms, except for irritability and frustration related to her poor cognition. The psychiatrist recommended lowering the dose of amitriptyline that she had been } \\
\text { taking for } 20 \text { years to treat her nerve pain from multiple sclerosis, as it might be contributing to her cognitive difficulties. Janet was very reticent to do this but her } \\
\text { PCP eventually persuaded her to agree to a very slow reduction. At her 6-month ATP study interview, she reported improved memory and concentration after finally } \\
\text { lowering the amitriptyline from } 100 \text { to } 75 \text { mg nightly, while at her 12-month ATP follow-up, when she was taking only } 50 \text { mg, her cognitive status was markedly } \\
\text { improved, and she stated on video that she was "very pleased" with her outcome and thanked the psychiatrist during her video interview. }\end{array}$ \\
\hline
\end{tabular}

This case demonstrates how a PCP and psychiatrist can work together to gradually improve the health of patients over time

ATP, asynchronous telepsychiatry.

less educated. We expect that the education differences will balance out once we meet our target enrollment. Case study examples of the utility of ATP in making care more efficient as an integrated stepped care choice are presented in Table 2.

\section{Discussion}

In this article, we present initial summary data and case findings of a 5-year study of a randomized controlled trial of ATP compared with STP. These results are being published at the end of the third year, before the end of patient enrollment and before analysis of any clinical or economic outcomes. Overall, we expect to find ATP to be administratively simpler and less costly to implement than STP. While acknowledging these caveats, it is evident that we do have some important early findings.

PCPs in the UC Davis Primary Care Network have consistently referred their patients to this study for 3 years in the knowledge that after acceptance into the study and randomization, they will receive either STP or ATP consults. We have had positive anecdotal feedback about the study impact for both STP and ATP patients from referring PCPs. The use of a common EMR by PCPs and psychiatrists has been a key component, increasing communication between the psychiatrists and PCPs, and this integrated communication component has strengthened the relationship between the PCPs and psychiatrists and aided coordination of care. We have devel- oped a training package for the role of the ATP interviewer, which is a new clinical role for mental health trained providers, including therapists, social workers, and counselors, within the primary care setting.

The cases illustrate the efficiency of this new model of care, where ATP consultations and a changed workflow may be an important part of the future integration of behavioral healthcare into the everyday workflow of the primary care setting. ATP adds to the suite of technologies available in the IPCMH and when implemented within an integrated system increases the suite of stepped care referral choices for PCPs when they wish to refer a patient for psychiatric assessment. We believe that there will be extensive changes to psychiatric work practices over the next decade, with psychiatrists increasingly working in team-based environments spreading their skills and expertise, and more frequently performing indirect consultations, such as the ATP consultations described here. This model would have positive impacts on the current workforce shortages the profession is facing, and will allow practicing psychiatrists to provide better care for larger populations of patients.

\section{Acknowledgment}

This project was funded with a Grant from the Agency for HealthCare Research and Quality R01HS021477-"A controlled trial of patient centered telepsychiatry interventions." 


\section{YELLOWLEES ET AL.}

\section{Disclosure Statement}

Michelle Burke Parish reports funding from the Betty Irene Moore Foundation during the conduct of the study. Dr. Chan reports grants from American Psychiatric Associationadministered fellowship-funded by U.S. Department of Health \& Human Services' Substance Abuse and Mental Health Services Administration, outside the submitted work. Dr. Scher reports grants from University of California Davis Practice Management Board Innovation Grant, during the conduct of the study. Dr. Shore is the Chief Medical Officer for AccessCare, which provides telemental health services. Dr. Xiong reports consultant fees from Blue Cross Blue Shield Federal Employee Program and salary from Doctor on Demand, during the study. For all other authors there is nothing to disclose.

\section{REFERENCES}

1. Peek CJ. Integrated behavioral health and primary care: $A$ common language. In: Talen MR, Burke Valeras A, eds. Integrated behavioral health in primary care: Evaluating the evidence, identifying the essentials. New York: Springer New York, 2013:9-31.

2. Katon $W$, Von Korff M, Lin E, et al. Stepped collaborative care for primary care patients with persistent symptoms of depression: A randomized trial. Arch Gen Psychiatry 1999;56:1109-1115.

3. Unützer J, Katon W, Callahan CM, et al. Collaborative care management of late-life depression in the primary care setting: A randomized controlled trial. JAMA 2002;288:2836-2845.

4. Vimalananda VG, Gupte G, Seraj SM, et al. Electronic consultations (e-consults) to improve access to specialty care: A systematic review and narrative synthesis. J Telemed Telecare 2015;21:323-330.

5. Golberstein E, Kolvenbach S, Carruthers H, Druss B, Goering P. Effects of electronic psychiatric consultations on primary care provider perceptions of mental health care: Survey results from a randomized evaluation. Healthcare 2017; pii: S22130764(16)30173-7.

6. McWilliams JK. Integrating telemental healthcare with the patient-centered medical home model. J Child Adolesc Psychopharmacol 2016;26:278-282.

7. Hilty DM, Ferrer DC, Parish MB, Johnston B, Callahan EJ, Yellowlees PM. The effectiveness of telemental health: A 2013 review. Telemed J E Health 2013;19:444-454.

8. Pomerantz $A$, Cole BH, Watts BV, Weeks WB. Improving efficiency and access to mental health care: Combining integrated care and advanced access. Gen Hosp Psychiatry 2008;30:546-551.

9. Neufeld JD, Yellowlees PM, Hilty DM, Cobb $H$, Bourgeois JA. The e-mental health consultation service: Providing enhanced primary-care mental health services through telemedicine. Psychosomatics 2007;48:135-141.

10. Ruskin PE, Silver-Aylaian M, Kling MA, et al. Treatment outcomes in depression: Comparison of remote treatment through telepsychiatry to in-person treatment. Am J Psychiatry 2004;161:1471-1476.

11. Wootton R, Yellowlees P, McLaren P. Telepsychiatry and e-mental health. Road Lake, IL: Royal Society of Medicine Press, Ltd., 2003.

12. Bashshur RL, Shannon GW, Bashshur N, Yellowlees PM. The empirical evidence for telemedicine interventions in mental disorders. Telemed J E Health 2016;22:87-113.

13. Yellowlees $P$, Odor A, Burke Parish M, losif AM, Haught $K$, Hilty D. A feasibility study of the use of asynchronous telepsychiatry for psychiatric consultations. Psychiatr Serv 2010;61:838-840.

14. Odor A, Yellowlees P, Hilty D, Burke Parish M, Nafiz N, losif AM. PsychVACS: A system for asynchronous telepsychiatry. Telemed J E Health 2011;17:299303.

15. Butler TN, Yellowlees P. Cost analysis of store-and-forward telepsychiatry as a consultation model for primary care. Telemed J E Health 2012;18:74-77.

16. Yellowlees PM, Odor A, Parish MB. Cross-lingual asynchronous telepsychiatry: Disruptive innovation? Psychiatr Serv 2012;63:945

17. First MB, Gibbon M, Spitzer RL, Benjamin LS. User's guide for the structured clinical interview for DSM-IV axis II personality disorders: SCID-II. Washington, DC: American Psychiatric Publishing, 1997.

18. Scher LM, Fisher TJ, Summers SM. Psychiatric interview. Medscape 2016. Available at http://emedicine.medscape.com/article/1941476-overview (last accessed July 29, 2017).

19. Malowney M, Keltz S, Fischer D, Boyd JW. Availability of outpatient care from psychiatrists: A simulated-patient study in three US cities. Psychiatr Serv 2014;66:94-96.

Address correspondence to: Peter Yellowlees, MBBS, MD Department of Psychiatry University of California, Davis 2230 Stockton Boulevard Sacramento, CA 95817

E-mail: pmyellowlees@ucdavis.edu

Received: April 27, 2017

Revised: July 13, 2017

Accepted: July 13, 2017

Online Publication Date: October 12, 2017 